\title{
A Study of the Major Pathogens Causing Fruit Rots of Apple in Shelf Life in Hangzhou, Zhejiang Province, China
}

\author{
Yangying Sun ${ }^{1 \#, ~ M i n l i ~ L i n ~}{ }^{1 \#, ~ Y u a n z h i ~ C h e n ², ~ X u a n ~ C h e n ' 1, ~ Y e ~ C a i ', ~ H u a b i n ~ L u o ~}{ }^{1}$, Ting Zhou ${ }^{*}$ \\ ${ }^{1}$ Hangzhou Key Laboratory for Safety of Agricultural Products, College of Life and Environmental Science, \\ Hangzhou Normal University, Hangzhou, China \\ ${ }^{2}$ Research Centre for Plant RNA Signaling, College of Life and Environmental Science, \\ Hangzhou Normal University, Hangzhou, China \\ Email: *zt20100061@163.com
}

How to cite this paper: Sun, Y.Y., Lin, M.L., Chen, Y.Z., Chen, X., Cai, Y., Luo, H.B. and Zhou, T. (2019) A Study of the Major Pathogens Causing Fruit Rots of Apple in Shelf Life in Hangzhou, Zhejiang Province, China. American Journal of Plant Sciences, 10, 2070-2085.

https://doi.org/10.4236/ajps.2019.1011146

Received: October 10, 2019

Accepted: November 25, 2019

Published: November 28, 2019

Copyright $\odot 2019$ by author(s) and Scientific Research Publishing Inc. This work is licensed under the Creative Commons Attribution International License (CC BY 4.0).

http://creativecommons.org/licenses/by/4.0/

\section{(c) (i) Open Access}

\begin{abstract}
Major pathogens causing fruit rots of apple in shelf life in Hangzhou, a city in east China, were identified by rDNA-ITS analysis. Their pathogenicities and stress tolerances were compared as well. Combining with disease symptoms, colonial phenotypes and mycelial microscopic morphology, the fungi were determined as Penicillium expansum, Botrytis cinerea, Botryosphaeria dothidea, Diaporthe phaseolorum, Alternaria alternata and Fusarium acuminatum, respectively. Among them, $B$. cinerea and $B$. dothidea showed a higher pathogenicity; $B$. cinerea and $D$. phaseolorum were hardly affected by the temperature at a range of $15^{\circ} \mathrm{C}$ and $25^{\circ} \mathrm{C} ; B$. cinerea has the highest resistant to Thiabendazole and $D$. phaseolorum displayed the strongest resistance to Imazalil; and $P$. expansum was most sensitive to ultraviolet light radiation. The results provide some useful information that helps to combine conventional and alternative control strategies to minimize apple postharvest losses in shelf life.
\end{abstract}

\section{Keywords}

Apple, rDNA-ITS, Fungal Pathogenicity, Ultraviolet-Light Radiation, Fungicides

\section{Introduction}

Apple (Malus pumila) is a kind of popular edible fruit with a moderate content of dietary fiber and many healthy nutritions including various vitamins and "Yangying Sun and Minli Lin contributed equally to this work. 
minerals. Apples are commonly eaten fresh, consumed in juice or as an important ingredient in many desserts. In 2017, the apple production of China was 41.39 million tonnes accounting for $49.79 \%$ of the world total

(http://www.fao.org/faostat/en/\#data/QC). To furnish the market all along the year, it has been necessary to develop strategies to enlarge the storage period and shelf life. The cold storage and fungicide treatment are the most effective methods for long term purpose [1]. However, the apples with higher commercial value are susceptible to infection by pathogenic fungi in ambient temperature during fruit shipping or shelf life, which causes rotting and makes fruit lost their commodity attributes including discoloration, production of off-flavor, deterioration in nutritional quality, reduction in pulp quality and mycotoxin contamination. To minimize latent infection and decay incidence in shelf life, storing fruit in polyethylene bags, coating with wax, lowering storage temperature, and treating with fungicide have been reported [2] [3].

However, mounting concerns of consumers and sellers about chemical residues in food and energy consumption have driven the search for more precise management strategies that are effective, convenient and energy-efficient. It is essential to explicitly understand the local popular pathogenic fungi in a particular geographical area or particular environmental conditions. Due to climate and soil conditions, the Zhejiang province region is not suitable for apple growth. Most of the apple products come from other domestic producing areas such as the Bohai Gulf region, the Loess Plateau region, the Ancient Yellow River Course Basin region, the Northeast and Northwest Cool Region and the Southeast Plateau Temperate region [4]. Because fresh fruit is mainly stored in the producing area, microbial wastage in the course of transit or in shelf life has been the main concern in the Zhejiang area. As the capital of Zhejiang province and the south-central portion of the Yangtze River Delta, Hangzhou possesses a huge consumer market of fresh apple fruit and sustained consumption growth potential. Therefore, postharvest diseases of apples in Hangzhou local market are representative. Identification of distinguishing causal pathogens will probably help to accurately formulate more effective integrated strategies for controlling the postharvest diseases of apples in shelf life and minimizing economic damage. In the present study, the major pathogenic fungi of apples during shelf life in Hangzhou were collected and identified by phenotypic and molecular biological analyses. The pathogenicity and sensitivities on temperature, fungicides and ultraviolet-light exposure of fungi were also determined.

\section{Materials and Methods}

\subsection{Fungal Isolation and Identification}

Naturally infected apples (Malus domestica Borkh. cv. Red Fuji) most with changed color, musty-smelling, watery internal tissues were collected from a total of 10 supermarkets which respectively located in Jianggan district, Xihu district, Gongshu district, Yuhang district, Xiaoshan district of Hangzhou city. The 
apple with apparent disease was cleansed with $70 \%$ ethanol and removed the peel. The pulp at the advancing edges of the lesion was diced (about $0.2 \mathrm{~cm} \times 0.2$ $\mathrm{cm} \times 0.2 \mathrm{~cm}$ ) by a sterilized scalpel and placed on potato dextrose agar (PDA) plates. After 5 days of culturing at $25^{\circ} \mathrm{C}$ in a BGZ Series II constant temperature incubator (Boxun, China), a mycelial agar $(0.5 \mathrm{~cm}$ diameter $)$ obtained from the growing edge of a colony was subcultured on PDA medium. Repeat this step until the specific colonial phenotype was stable. The images of fungal colonies and infected apples were photographed using an EOS 60D digital camera (Canon, Japan). The images of fungal mycelia or conidia of isolated were captured by a microscope with a DS-Fil digital microscope camera head (Nikon, Japan).

The fungal DNA was extracted using a DNeasy Plant Mini Kit (Qiagen, Germany) according to the product description. The internal transcribed spacer region of ribosomal DNA (rDNA-ITS) was amplified using a PrimeSTAR HS DNA Polymerase (Takara, Japan) and a pair of universal primers ITS4 and ITS5 in an S1000 thermal cycler (Bio-Rad, USA) [5]. The amplified products were analyzed by $1 \%$ agarose gel electrophoresis, purified utilizing a High Pure PCR Product Purification Kit (Roche, Switzerland) and sequenced using a service from Invitrogen of Thermo Fisher Scientific (USA). The sequencing results of rDNA-ITS were analyzed by Nucleotide BLAST of Web Basic Local Alignment Search Tool

(https://blast.ncbi.nlm.nih.gov/Blast.cgi?PROGRAM=blastn\&PAGE_TYPE=Blas tSearch\&LINK_LOC=blasthome).

\subsection{Evaluating Fungal Pathogenicity}

Apples (Malus domestica Borkh. Cv. Red Fuji) with almost equal size, similar maturity and without mechanical injury were obtained from the local market. The fruit were disinfected by sodium hypochlorite (2\%) for $2 \mathrm{~min}$, cleansed by water twice and air-dried at room temperature in a fume hood. Each apple fruit was punctured using a sterilized borer at its equatorial region. Then, a mycelial agar $(0.5 \mathrm{~cm}$ diameter $)$, which was obtained from the edge of the colony cultured for 5 days at $25^{\circ} \mathrm{C}$, was put on the wound. All apples were stored at $25^{\circ} \mathrm{C}$ in plastic crates with plastic film to keep an $80 \%$ humidity. The disease incidence was evaluated and lesion diameter was measured using the decussation method every two days. There were 10 apples for each pathogen with three replicates. The experiment was conducted twice.

\subsection{Sensitivity Tests to Temperature, Fungicides and Ultraviolet-Light Radiation}

A mycelial agar disc $(0.5 \mathrm{~cm}$ diameter $)$ as described above was placed on the center of a petri dish $(9 \mathrm{~cm})$ containing $25 \mathrm{~mL}$ PDA. The plates were cultured under a stationary state at $25^{\circ} \mathrm{C}$ or $15^{\circ} \mathrm{C}$ for 8 days in a constant temperature incubator. The colonial diameters were determined daily by the decussation method. Briefly, the longitude diameter and latitude diameter of each colony were measured respectively using a millimeter scale ruler. Then, the diameter 
mean was used to evaluate the mycelial expansion capability of each fungus. There were 6 plates for each temperature and each pathogen with three replicates. The experiment was conducted twice.

A mycelial agar disc $(0.5 \mathrm{~cm}$ diameter $)$ as described above was placed on the center of a petri dish $(9 \mathrm{~cm})$ containing $25 \mathrm{~mL}$ PDA with $0,0.5,1.0,2.0$ or 4.0 $\mathrm{mg} / \mathrm{L}$ Imazalil (Sigma, USA), as well as $0,25,50,100$, or $200 \mathrm{mg} / \mathrm{L}$ Thiabendazole (Sigma, USA). The plates were cultured under a stationary state at $25^{\circ} \mathrm{C}$ for 5 days in a constant temperature incubator. The minimal lethal concentration of Imazalil or Thiabendazole for different pathogens was evaluated by mycelial growth status. There were 6 plates for each fungicide treatment and each pathogen with three replicates. The experiment was conducted twice.

A mycelial agar disc $(0.5 \mathrm{~cm}$ diameter $)$ as described above was placed on the center of a petri dish $(9 \mathrm{~cm})$ containing $25 \mathrm{~mL}$ PDA. The plates were exposed to an ultraviolet lamp (wave: $253.7 \mathrm{~nm}$; power: $20 \mathrm{~W}$; intensity: $30 \mu \mathrm{W} / \mathrm{cm}^{2}$ ) with a distance of $70 \mathrm{~cm}$ for 0 to $300 \mathrm{~min}$. After that, they were cultured at $25^{\circ} \mathrm{C}$ for 5 days in a constant temperature incubator. The mycelial growth rate was used to estimate the sensitivity of pathogen to ultraviolet-light radiation. If the growth rate of pathogen exposed to radiation was reduced and the colonial diameter was higher than $80 \%$ of control, the irradiation intensity of ultraviolet was considered as effective. If the colonial diameter was less than $80 \%$ of control, the irradiation intensity of ultraviolet was considered as significantly effective. There were 6 plates for each ultraviolet irradiation intensity and each pathogen with three replicates. The experiment was conducted twice.

\subsection{Statistical Analysis}

Data were pooled across independent repeat experiments and were performed by Statistical Product and Serviced Solutions (SPSS, USA). Analysis of variance (ANOVA) was used to compare more than two means. Mean separations were analyzed using Duncan's multiple range test. Differences at $p<0.05$ were considered to be significant.

\section{Results}

\subsection{Identification of Pathogens by Mycological Characteristics and Molecular Data}

According to the observation of the phenotypes of infected apples, a total of 13 apples almost covering all the notably disease symptoms were finally used for pathogen isolation. The 15 pathogen candidates were isolated, maintained on the PDA plates, and reinoculated on the apples (Figure 1). Among them, nine candidates were highly pathogenic to apples. After amplification using ITS4 and ITS5 universal primer pairs, rDNA-ITS fragment about 500 - 600 bp for each pathogen was obtained, sequenced and mega blasted (Figure S1). The rDNA-ITS sequences of six isolated pathogens numbered as P1 to P6 were well matched to those of six pathogenic fungi, and at least $97 \%$ identity was shared for each pathogen (Table 1). The detailed sequence information of each fungal 


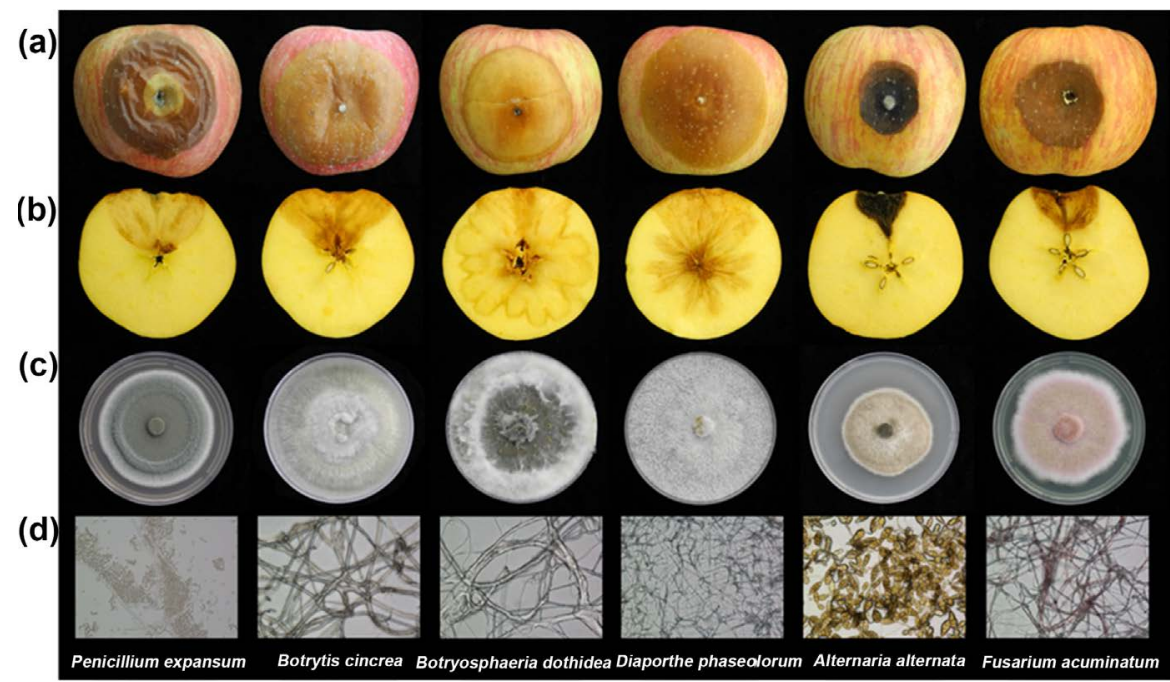

Figure 1. The phenotypes of isolated pathogens. (a) and (b) The surfaces and cross sections of apple fruit inoculated by indicated pathogens after 6 days of inoculation at $25^{\circ} \mathrm{C}$; (c) The colonial morphologies of isolated pathogens; (d) Microscopic observation of isolated pathogens.

Table 1. Sequencing and matching results using ITS universal primers of isolated pathogens.

\begin{tabular}{cccccccc}
\hline NO. & $\begin{array}{c}\text { ITS length } \\
(\mathrm{bp})\end{array}$ & Accession & $\begin{array}{c}\text { Query cover } \\
(\%)\end{array}$ & Score & $\begin{array}{c}\text { Identities } \\
(\%)\end{array}$ & Gaps & Species \\
\hline P1 & 602 & KX243329.1 & 100 & 1040 & 97 & 2 & Penicillium expansum \\
P2 & 564 & MH871883.1 & 98 & 937 & 96 & 4 & Botrytis cinerea \\
P3 & 566 & MH715249.1 & 98 & 976 & 97 & 2 & Botryosphaeria dothidea \\
P4 & 584 & AF001026.2 & 92 & 968 & 98 & 0 & Diaporthe phaseolorum \\
P5 & 565 & MK078593.1 & 100 & 1011 & 98 & 0 & Alternaria alternata \\
P6 & 577 & MK050649.1 & 99 & 983 & 97 & 3 & Fusarium acuminatum \\
\hline
\end{tabular}

rDNA-ITS was represented by Table S1. Morphological data also provided solid evidence to confirm the genetic backgrounds of isolated pathogens, such as the spherical or elliptical conidia with a dull green color for P1, a collapsed and water-soaked appearance on apple for P2, the cankers of white rot on apple for P3, white, immersed, branched, septate mycelium for $\mathrm{P} 4$, hyaline obpyriform or ellipsoid conidia with a short conical beak at the tip for P5, and pink or reddish colonies for P6. Combining with disease symptoms, colonial phenotypes and mycelial microscopic morphology, P1 to P6 were identified as Penicillium expansum, Botrytis cinerea, Botryosphaeria dothidea, Diaporthe phaseolorum, Alternaria alternata, Fusarium acuminatum in order (Figure 1). Besides, an isolated fungus numbered as P7 was noticed for fast growth and lower pathogenicity to apple fruit. Basing on morphological and genetic analysis, it was identified as Trichoderma harzianum which was an important biocontrol agent against various fungal phytopathogens (Figure S2). 


\subsection{Comparision of Pathogenicity in Vivo}

Through the artificial infection test, the six fungi were highly pathogenic to apples, and disease incidence of apples after needle puncturing inoculation of them achieved 100\% within $48 \mathrm{~h}$. Through analysis of lesion expansion, P2, P3 and P4 have similar and fastest growth rates among six pathogens, followed by P1. Through observing the cross section of inoculated apples, P3 and P4 showed higher pathogenicity than P2. The growth rates of P5 and P6 were the lowest, and there were no significant differences between them (Figure 2). In vitro, pathogens according to decreasing growth rates were in turn as follows: P3, P2, P4, P1, P5 and P6 (Figure 3). The sequence was approximately the same as that in vivo.

\subsection{Sensitivity Comparison of Pathogens to Temperature, UV-Light Irradiation and Fungicide}

To determine the effect of temperature on fungal development, the isolated pathogens were cultured at $25^{\circ} \mathrm{C}$ and $15^{\circ} \mathrm{C}$ which simulate ambient temperatures or that in and air-cooled fresh-keeping cabinet. The results indicated that lower temperature could significantly inhibit the growth of P1, P3, P4 and P5. Comparing with those at $25^{\circ} \mathrm{C}$, the growth rates of $\mathrm{P} 3$ and $\mathrm{P} 5$ declined even more than $50 \%$ at $15^{\circ} \mathrm{C}$. However, the growth of $\mathrm{P} 2$ and $\mathrm{P} 4$ was hardly affected by the temperature at a range of $25^{\circ} \mathrm{C}$ and $15^{\circ} \mathrm{C}$ (Figure 3).

Imazalil (one of the group of imidazoles) and Thiabendazole (belong to the chemical class of benzimidazoles) are two typical fungicides that were generally applied to control postharvest pathogens. The fungitoxic action of Thiabendazole was binding with microtubules in the cell wall, while Imazalil affected fungal ergosterol biosynthesis and the cellular permeability barrier. In this study, resistances of the isolated pathogen to two fungicides were assessed. Various

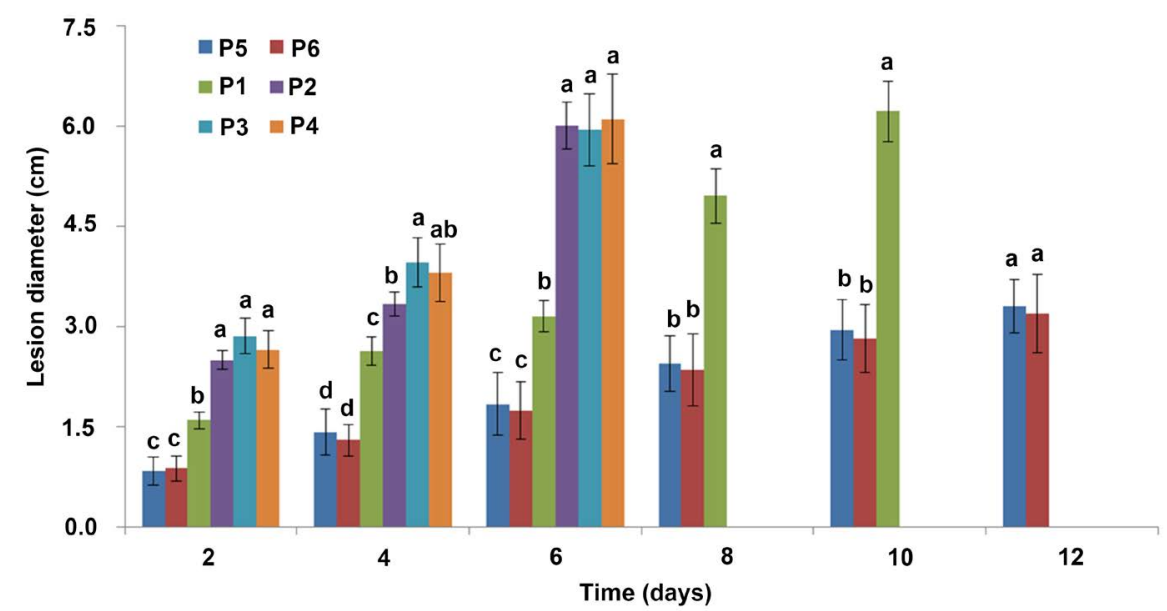

Figure 2. The lesion diameters of isolated pathogens in apple fruit during 12 days of storage at $25^{\circ} \mathrm{C}$. Bars represent the standard deviation of the means of three independent experiments. Lower case letters indicated significant differences at $P<0.05$ at each time point. P1: Penicillium expansum; P2: Botrytis cinerea; P3: Botryosphaeria dothidea; P4: Diaporthe phaseolorum; P5: Alternaria alternata; P6: Fusarium acuminatum. 

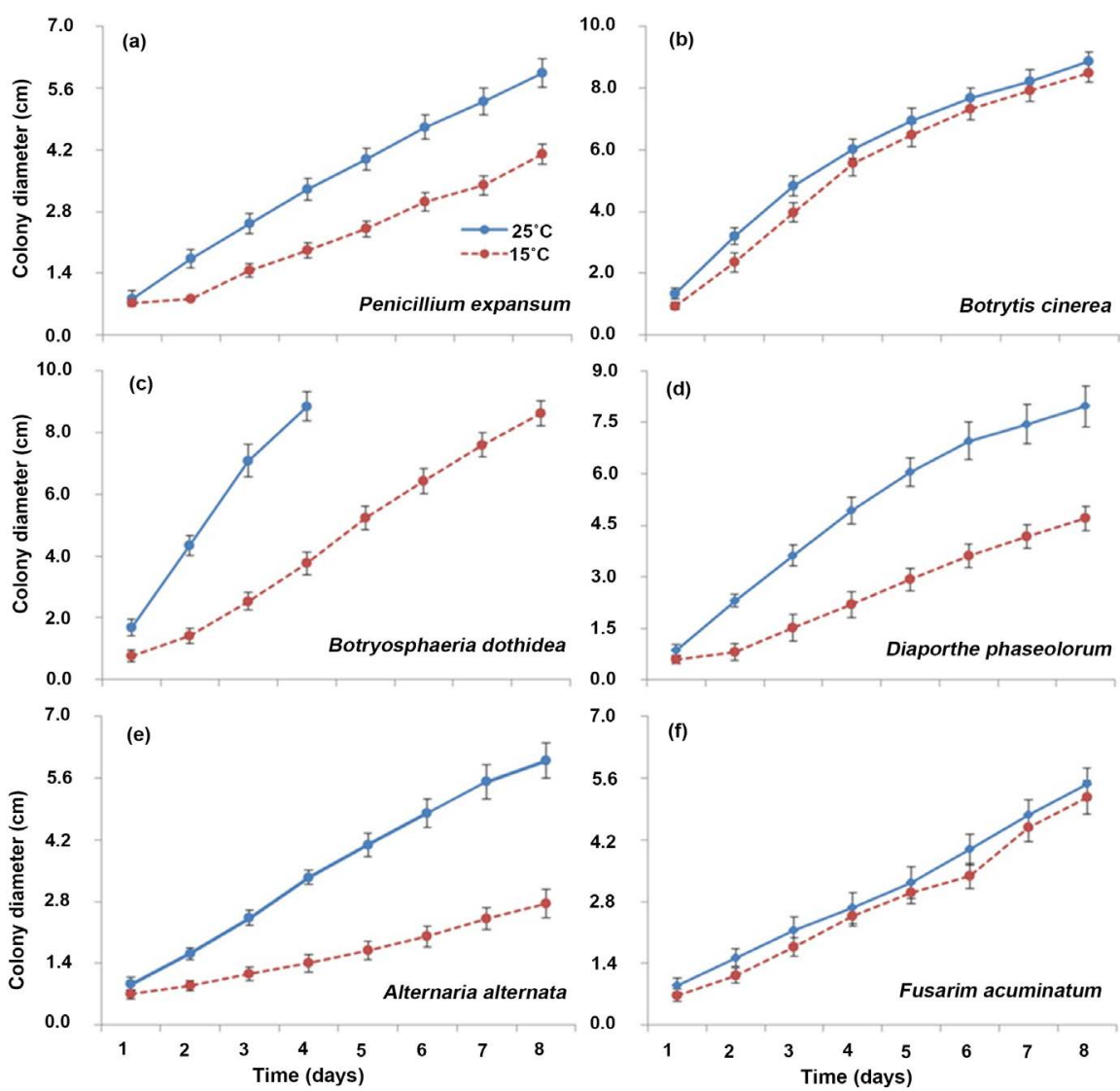

Figure 3. The effects of temperature on the mycelial growth of isolated pathogens.

sensitivities of different pathogens against fungicides were observed. Pathogens according to reducing susceptibility to Imazalil were in turn as follows: P3, P2, P6, P5, P4 and P1. All the isolated pathogens could be killed by Imazalil with a concentration of $4.0 \mathrm{mg} / \mathrm{L}$ except P3. Pathogens according to reducing susceptibility to Thiabendazole were in turn as follows: P2, P5, P3, P6, P4 and P1. All the isolated pathogens could be killed by Thiabendazole with a concentration of 200 $\mathrm{mg} / \mathrm{L}$ except P2 (Table 2).

The effect of UV-light irradiation on the development of isolated pathogens was investigated. The results indicated the growth of all pathogens could be delayed with UV-light irradiation time increasing. However, the resistances of isolated pathogens to UV-light were different from each other. For example, UV-light irradiation with doses of $2.5 \times 105 \mu \mathrm{W} \cdot \mathrm{s} / \mathrm{cm}^{2}$ can significantly retard the development of P1; Nevertheless, it did not affect the growth of P2 until irradiation doses reached $4.0 \times 10^{5} \mu \mathrm{W} \cdot \mathrm{s} / \mathrm{cm}^{2}$. Also, effective doses of UV-light irradiation for $\mathrm{P} 3$ and $\mathrm{P} 5$ were nearly identical. Pathogens according to reducing susceptibility to UV-light irradiation were in turn as follows: P1, P4, P6, P3, P5 and P2 (Table 3).

\section{Discussion}

Due to microbiological spoilage, fruit and vegetables exhibit huge postharvest 
Table 2. The sensitive detection of isolated pathogens on Imazalil and thiabendazole.

\begin{tabular}{|c|c|c|c|c|c|c|c|c|c|c|}
\hline \multirow{2}{*}{ Pathogens } & \multicolumn{5}{|c|}{ Imazalil (mg/L) } & \multicolumn{5}{|c|}{ Thiabendazole (mg/L) } \\
\hline & 0 & 0.5 & 1.0 & 2.0 & 4.0 & 0 & 25 & 50 & 100 & 200 \\
\hline Penicillium expansum & $\circ$ & $\circ$ & $\bullet$ & $\bullet$ & $\bullet$ & $\circ$ & $\circ$ & $\bullet$ & $\bullet$ & $\bullet$ \\
\hline Botrytis cinerea & $\circ$ & $\circ$ & $\circ$ & $\circ$ & $\bullet$ & $\circ$ & $\circ$ & $\circ$ & $\circ$ & $\circ$ \\
\hline Botryosphaeria dothidea & $\circ$ & ○ & $\circ$ & $\circ$ & $\circ$ & $\circ$ & $\circ$ & $\bullet$ & $\bullet$ & $\bullet$ \\
\hline Diaporthe phaseolorum & $\circ$ & $\circ$ & $\bullet$ & $\bullet$ & $\bullet$ & $\circ$ & $\circ$ & $\bullet$ & $\bullet$ & $\bullet$ \\
\hline Alternaria alternata & $\circ$ & $\circ$ & $\circ$ & $\bullet$ & $\bullet$ & $\circ$ & $\circ$ & $\circ$ & $\circ$ & $\bullet$ \\
\hline Fusarium acuminatum & $\circ$ & $\circ$ & $\circ$ & $\circ$ & $\bullet$ & $\circ$ & $\circ$ & $\bullet$ & $\bullet$ & $\bullet$ \\
\hline
\end{tabular}

The "•" indicates "lethal" and the "о" indicates "non-lethal".

Table 3. The insensitive detection of isolated pathogens on ultraviolet light radiation.

\begin{tabular}{|c|c|c|c|c|c|c|c|c|c|c|}
\hline \multirow{2}{*}{ Pathogens } & \multicolumn{10}{|c|}{ UV intensity $\left(1 \times 10^{5} \mu \mathrm{W} \cdot \mathrm{s} / \mathrm{cm}^{2}\right)$} \\
\hline & 0 & 1.0 & 1.5 & 2.0 & 2.5 & 3.0 & 3.5 & 4.0 & 4.5 & 5.0 \\
\hline Penicillium expansum & $\circ$ & $\circ$ & - & $\bullet$ & $\bullet$ & $\bullet$ & $\bullet$ & $\bullet$ & $\bullet$ & $\bullet$ \\
\hline Botrytis cinerea & $\circ$ & $\circ$ & $\circ$ & $\circ$ & $\circ$ & $\circ$ & $\circ$ & $\bullet$ & $\bullet$ & $\bullet$ \\
\hline Botryosphaeria dothidea & $\circ$ & $\circ$ & $\circ$ & $\circ$ & $\circ$ & $\bullet$ & $\bullet$ & $\bullet$ & $\bullet$ & $\bullet$ \\
\hline Diaporthe phaseolorum & $\circ$ & $\circ$ & $\circ$ & $\bullet$ & $\bullet$ & $\bullet$ & $\bullet$ & $\bullet$ & $\bullet$ & $\bullet$ \\
\hline Alternaria alternata & $\circ$ & $\circ$ & $\circ$ & $\circ$ & $\circ$ & $\bullet$ & - & - & $\bullet$ & $\bullet$ \\
\hline Fusarium acuminatum & ० & ० & ० & 0 & • & • & $\bullet$ & $\bullet$ & $\bullet$ & • \\
\hline
\end{tabular}

The "•" indicates "significantly effective"; the "॰" indicates "effective"; and the "o" indicates "noneffective".

losses even to the extent of $35 \%$ during the various stage of storage, transportation, and marketing. Especially, the physiological and biochemical attributes of fresh products will distinctly change, and susceptibility against postharvest microbes will significantly increase at the retailer's market shelf after a long term of cold storage. The application of synthetic fungicides is an effective approach to postharvest disease management. However, the fungicide with a high dose could promote the development of resistant pathogens, and the residues have an adverse effect on public health and the environment. To meet safe, power-saving and environmental-protection requirements, developing more scientific, reasonable and efficient control measures is necessary and encouraged. The fundamental premise of research efforts is precisely understanding the major diseases and their characteristics in local markets. Then, synthetic chemical fungicides with a lower toxicity, potent disinfectants, elicitors that can induce host resistance, microbial antagonists, some chemical alternatives generally regarded as safe substances, antifungal edible coating, low temperature or controlled atmosphere can be efficiently applied in an independent or integrated way [1] [6] [7] [8].

In the present study, six causal agents of postharvest apple fruit diseases were isolated and identified. Among them, P. expansum, a psychrophilic blue mold, is 
one of the most important and damaging postharvest pathogens. It can infect a wide range of fruit and vegetables, particularly pome fruit and derived products. Fruit infected by $P$. expansum has a musty smell and light-brown (or dark-brown) lesions containing white mycelium and blue spore masses. $P$. expansum also produces many kinds of secondary metabolites including citrinin, patulin, terretonin, conidial pigments, loline, etc. [9]. Patulin is a highly toxic mycotoxin and may result in nephrotoxicity, neurotoxicity, hepatotoxicity, teratogenicity, genotoxicity and mutagenicity in the human body [10]. Massive research efforts on the genome, transcriptome, and metabolites analysis have provided important information relevant to understanding the molecular basis of patulin biosynthesis [11] [12].

Grey mold, incited by Botrytis cinerea, is named for its plentiful grey, branching tree-like conidia. Botrytis cinerea is thermophilic, hygrophilous and fast-growing. It could colonize the injury, stem end or calyx end of the fruit and vegetables, and spread to the entire host. The infected hosts have a collapsed and water-soaked appearance. As a necrotrophic fungus, it can lead to significant economic losses due to a broad host range such as grape, strawberry, apple, kiwi, tomato, bulb crops and many others [13] [14]. Integrated management of grey mold has been reviewed by Romanazzi et al. [15].

Botryosphaeria dothidea is a destructive pathogen and the causal agent of cankers on a wide variety of plant hosts. $B$. dothidea infection is a significant threat to the fruit and vegetable industry worldwide, particularly in East Asia [16]. It can cause white or ring rot of apple fruit in most of the commercial cultivars. The symptom exhibits slightly sunken lesions with alternating tan and light brown colors [17]. Reduced lenticels and microcracks and increased cuticular wax thickness can lower the susceptibility of apple to B. dothidea [18]. Pathogenesis-related protein- 4 was involved in the defense responses of apple against $B$. dothidea through both jasmonate (JA) and salicylic acid (SA) signaling pathway [19]. B. dothidea is also sensitive to benomyl, keresoxim-methyl, trifloxystrobin, and tebuconazole [20] [21].

Diaporthe phaseolorum belonging to the sub-class Hymenoascomycetidae of the class Ascomycetes is responsible for many plant disease symptoms such as stem, twig and branch cankers, seed decay, shoot necrosis, pod blight fruit and root rot [22]. It can pose a great risk due to its wide distribution, high pathogenicity and virulence. Two phytotoxic metabolites of 5-deoxybostrycoidin and fusaristatin A produced by D. phaseolorum SKS019 exhibit cytotoxicity or growth inhibitory activity to human cell lines in vitro [23]. Glycine soja, Euphorbia neriifolia, Vitis vinifera, Actinidia chinensis, Jatropha curcas have been reported as its hosts in China [24] [25].

Alternaria alternata is an opportunistic and saprophytic pathogen that can produce many mycotoxins including alternariol, alternariol monomethyl ether, altertoxins, altenuene, L-tenuazonic acid [26]. It can also induce asthma, upper respiratory tract infections and keratitis in humans [27] [28]. For postharvest fruit, black rot or black spot caused by $A$. alternata has been reported in many 
hosts such as citrus, tomato, peach, jujube, kiwifruit [29] [30] [31]. The characteristics of $A$. alternata conidia were pale brown to olive brown, obclavate to ellipsoid in shape, and with a short beak at the tip. These conidia can be produced in lesions from ten days after the symptoms appearing, and this production process can last about forty days [32]. Many measures have been developed to control this pathogen; however, the disease can hardly be completely eradicated due to wide distribution, efficient conidial production, rapidly spreading.

The genus Fusarium contains numerous species of economic importance due to their ability to cause plant diseases and to produce mycotoxins such as fumonisins, trichothecenes and zearalenone [33]. Among them, Fusarium acuminatum without microconidia can form a whitish-pink and partly carmine aerial mycelium, and produce dark red pigmentation in the medium [34]. The phenotype of P6 isolate was consistent with the typical colony morphology of $F$. acuminatum. Many reports have indicated that $F$. acuminatum can cause tomato, Vaccinium corymbosum, Ginseng, Kiwifruit, potato plant or fruit rot [35] [36] [37] [38] [39]. Apple fruit rot caused by F. acuminatum was identified in the present study.

In addition, the genus Trichoderma is widely distributed in decaying wood and vegetable matter due to a close symbiotic association with plants. Most of the strains are rarely cause diseases in living plants. Among different species, $T$. harzianum is recognized for its antagonist ability against various fungal pathogens, and largely exploited in disease control [40]. The key biocontrol genes of $T$. harzianum, such as tris5, Thp G1,Th-Chit, erg1, thkel1 and qid 74 , are related to stress resistance, cell wall damaging, mycelial development, and parasitic activity [41] [42]. In the present study, T. harzianum was also found in lesions of apple fruit affected by other pathogenic fungi. That indicated that $T$. harzianum has a potential to be as a biocontrol agent in postharvest apple storage.

The identified pathogens can attack apples with different infection mechanisms. Meanwhile, different pathogens with various attributes have reacted differently to the same management program. For example, in this study, $P$. expansum is most susceptible to fungicide, Botrytis cinerea has the highest resistance to UV-light radiation, and Botryosphaeria dothidea is most sensitive to temperature. Therefore, using stand-alone treatment cannot provide the efficacy, consistency, safety and energy efficiency required for commercial situations. Understanding the clear genetic background and biological characteristics of pathogens will encourage to develop integrated postharvest control measures with more scrutiny, elaborate design and technological innovation.

\section{Conclusion}

In conclusion, six major pathogens causing fruit rots of apple in shelf life in Hangzhou local markets and a potential biocontrol agent were identified in this study. Among them, $B$. cinerea and $B$. dothidea showed a higher pathogenicity. $B$. cinerea and $D$. phaseolorum were insensitive to the temperature at a range of $15^{\circ} \mathrm{C}$ and $25^{\circ} \mathrm{C}$. B. cinerea and D. phaseolorum exhibited a higher resistance to 
Thiabendazole and Imazalil respectively. Penicillium expansum was most sensitive to ultraviolet light radiation. The results provide some useful information which helps to combine conventional and alternative control strategies to minimize apple postharvest losses in shelf life.

\section{Acknowledgements}

This work was supported by the Zhejiang Provincial Natural Science Foundation of China (LY19C200010) and the Undergraduate Starlight Project for Innovation and Entrepreneurship of Hangzhou Normal University.

\section{Conflicts of Interest}

The authors declare no conflicts of interest regarding the publication of this paper.

\section{References}

[1] Morales, H., Marín, S., Ramos, A.J. and Sanchis, V. (2010) Influence of Post-Harvest Technologies Applied during Cold Storage of Apples in Penicillium expansum Growth and Patulin Accumulation: A Review. Food Control, 21, 953-962. https://doi.org/10.1016/j.foodcont.2009.12.016

[2] León-Zapata, M.A.De., Sáenz-Galindo, A., Rojas-Molina, R., Rodríguez-Herrera, Jasso-Cantú, D. and Aguilar, C.N. (2015) Edible Candelilla Wax Coating with Fermented Extract of Tarbush Improves the Shelf Life and Quality of Apples. Food Packaging and Shelf Life, 3, 70-75. https://doi.org/10.1016/j.fpsl.2015.01.001

[3] Mohammed, M., Bridgemohan, P., Mohamed, M.S., Bridgemohan, R.S.H. and Mohammed, Z. (2017) Postharvest Physiology and Storage of Golden Apple (Spondias cythera sonnerat or Spondias dulcis Forst): A Review. Journal of Food Processing \& Technology, 8, Article ID: 1000707. https://doi.org/10.4172/2157-7110.1000707

[4] Li, H., Wan, Y.Z., Wang, M., Han, M.Y. and Huo, H.X. (2015) History, Status and Prospects of the Apple Industry in China. Journal of the American Pomological Society, 69, 174-185.

https://www.researchgate.net/publication/287202013_Pecan_flavor_changes_durin g_storage\#page $=4$

[5] Lai, T.F., Bai, X.L., Wang, Y., Zhou, J.Y., Shi, N.N. and Zhou, T. (2015) Inhibitory Effect of Exogenous Sodium Bicarbonate on Development and Pathogenicity of Postharvest Disease Penicillium expansum. Scientia Horticulturae, 187, 108-114. https://doi.org/10.1016/j.scienta.2015.03.010

[6] Liu, J., Sui Y., Wisniewski, M., Droby, S. and Liu, Y.L. (2013) Review: Utilization of Antagonistic Yeasts to Manage Postharvest Fungal Diseases of Fruit. International Journal of Food Microbiology, 167, 153-160. https://doi.org/10.1016/j.ijfoodmicro.2013.09.004

[7] Feliziani, E., Lichter, A., Smilanick, J.L. and Ippolito, A. (2016) Disinfecting Agents for Controlling Fruit and Vegetable Diseases after Harvest. Postharvest Biology and Technology, 122, 53-69. https://doi.org/10.1016/j.postharvbio.2016.04.016

[8] Palou, L., Ali, A., Fallik, E. and Romanazzi, G. (2016) GRAS, Plant- and Animal-Derived Compounds as Alternatives to Conventional Fungicides for the Control of Postharvest Diseases of Fresh Horticultural Produce. Postharvest Biology and Technology, 122, 41-52. https://doi.org/10.1016/j.postharvbio.2016.04.017 
[9] Tannous, J., Keller, N.P., Atoui, A., Khoury, A.E., Lteif, R., Oswald, I.P. and Puel, O. (2018) Secondary Metabolism in Penicillium expansum: Emphasis on Recent Advances in Patulin Research. Critical Reviews in Food Science and Nutrition, 58, 2082-2098. https://doi.org/10.1080/10408398.2017.1305945

[10] Barad, S., Sionov, E. and Prusky, D. (2016) Role of Patulin in Postharvest Diseases. Fungal Biology Reviews, 30, 24-32. https://doi.org/10.1016/j.fbr.2016.02.001

[11] Ballester, A.R., Marcet-Houben, M., Levin, E., Sela, N., Selma-Lázaro, C., Carmona, L., Wisniewski, M., Droby, S., González-Candelas, L. and Gabaldón, T. (2015) Genome, Transcriptome, and Functional Analyses of Penicillium expansum Provide New Insights into Secondary Metabolism and Pathogenicity. Molecular Plant-Microbe Interactions, 28, 232-248. https://doi.org/10.1094/MPMI-09-14-0261-FI

[12] Zhou, T., Wang, X.H., Luo, J., Ye, B.S., Zhou, Y.Y., Zhou, L.W. and Lai, T.F. (2018) Identification of Differentially Expressed Genes Involved in Spore Germination of Penicillium expansum by Comparative Transcriptome and Proteome Approaches. Microbiology Open, 7, e562. https://doi.org/10.1002/mbo3.562

[13] Kan, J.A.L., Stassem, J.H.M., Mosbach, A., Lee, T.A.J.V.D., Faino, L., Farmer, A.D., Papasotiriou, D.G., Zhou, S., Seidl, M.F., Cottam, E., EDEL, D., Hahn, M., Schwartz, D.C., Dietrich, R.A., Widdison, S. and Scalliet, G. (2017) A Gapless Genome Sequence of the Fungus Botrytis cinera. Molecular Plant Pathology, 18, 75-89. https://doi.org/10.1111/mpp.12384

[14] Williamson, B., Tudzynski, B., Tudzynski, P. and Kan, J.A.L.V. (2007) Botrytis cinerea: The Cause of Grey Mould Disease. Molecular Plant Pathology, 8, 561-580. https://doi.org/10.1111/j.1364-3703.2007.00417.x

[15] Romanazzi, G., Smilanick, J.L., Feliziani, E. and Droby, S. (2016) Integrated Management of Postharvest Gray Mold on Fruit Crop. Postharvest Biology and Technology, 113, 69-76. https://doi.org/10.1016/j.postharvbio.2015.11.003

[16] Liu, Z.T., Lian, S., Li, B.H., Lu, H.Y., Dong, X.L. and Wang, C.X. (2016) Draft Genome Sequence of Botryosphaeria dothidea, the Pathogen of Apple Ring Rot American Society for Microbiology Journals, 4, e01142-16. https://doi.org/10.1128/genomeA.01142-16

[17] Tang, W., Ding, Z., Zhou, Z.Q., Wang, Y.Z. and Guo, L.Y. (2012) Phylogenetic and Pathogenic Analyses Show That the Causal Agent of Apple Ring Rot in China Is Botryosphaeria dothidea. Plant Disease, 96, 486-496. https://doi.org/10.1094/PDIS-08-11-0635

[18] Guan, Y.Q., Chang, R.F., Liu, G.J., Wang, Y., Wu, T., Han, Z.H. and Zhang, X.H. (2015) Role of Lenticels and Microcracks on Susceptibility of Apple Fruit to Botryosphaeria dothidea. European Journal of Plant Pathology, 143, 317-330. https://doi.org/10.1007/s10658-015-0682-Z

[19] Bai, S.H., Dong, C.H., Li, B.H. and Dai, H.Y. (2013) A PR-4 Gene Identified from Malus domestica Is Involved in the Defense Responses against Botryosphaeria dothidea. Plant Physiology and Biochemistry, 62, 23-32. https://doi.org/10.1016/j.plaphy.2012.10.016

[20] Brown-Rytlewski, D.E. and McManus, P.S. (2000) Virulence of Botryosphaeria dothidea and Botryosphaeria obtusa on Apple and Management of Stem Cankers with Fungicides. Plant Disease, 84, 1031-1037. https://doi.org/10.1094/PDIS.2000.84.9.1031

[21] Fan, K., Wang, J., Fu, L., Li, X.J., Zhang, Y., Zhang, X.D. and Zhai, H. (2016) Sensitive of Botryoshaeria dothidea from Apple to Tebuconazole in China. Crop Protec- 
tion, 87, 1-5. https://doi.org/10.1016/j.cropro.2016.04.018

[22] Danggomen, A., Visarathanonth, N., Manoch, L. and Piasai, O. (2013) Morphological Studies of Endophytic and Plant Pathogenic Phomopsis liquidambaris and Diaporthe phaseolorum ( $P$. phaseoli Anamorph) from Healthy Plants and Diseased Fruit. Thai Journal of Agricultural Science, 46, 157-164.

http://www.thaiagj.org/images/stories/Journal_online/2013/3/07-tj-agr-1013-66-p1 57-164.pdf

[23] Cui, H., Yu, J.C., Chen, S.H., Ding, M., Huang, X.S., Yuan, J. and She, Z.G. (2017) Alkaloids from the Mangrove Endophytic Fungus Diaporthe phaseolorum SKS019. Bioorganic \& Medicinal Chemistry Letters, 27, 803-807. https://doi.org/10.1016/j.bmcl.2017.01.029

[24] Dissanayake, A.J., Liu, M., Zhang, W., Chen, Z., Udayanga, D., Chukeatirote, E., Li X.H., Yan, J.Y. and Dyde, K.D. (2015) Morphological and Molecular Characterization of Diaporthe Species Associated with Grapevine Trunk Disease in China. Fungal Biology, 119, 283-294. https://doi.org/10.1016/j.funbio.2014.11.003

[25] Dissanayake, A.J., Phillips, A.J.L., Hyde, K.D., Yan, J.Y. and Li, X.H. (2017) The Current Status of Species in Diaporthe. Mycosphere, 8, 1106-1156.

https://doi.org/10.5943/mycosphere/8/5/5

[26] Scott, P. (2001) Analysis of Agricultural Commodities and Foods for Alternaria Mycotoxins. Journal of AOAC International, 84, 1809-1817.

[27] Xu, Y., Gao, C.W., Li, X.H., He, Y., Zhou, L.T., Pang, G.R. and Sun, S.T. (2013) In Vitro Antifungal Activity of Silver Nanoparticles against Ocular Pathogenic Filamentous Fungi. Journal of Ocular Pharmacology and Therapeutics, 29, 270-274. https://doi.org/10.1089/jop.2012.0155

[28] Gabriel, M.F., Postigo, I., Tomaz, C.T. and Martínez, J. (2016) Alternaria alternata Allergens: Markers of Exposure, Phylogeny and Risk of Fungi-Induced Respiratory Allergy. Environment International, 89-90, 71-80. https://doi.org/10.1016/j.envint.2016.01.003

[29] Li, L., Pan, H., Liu, W., Chen, M.Y. and Zhong, C.H. (2017) First Report of Alternaria alternata Causing Postharvest Rot of Kiwifruit in China. Plant Disease, 101, 1046. https://doi.org/10.1094/PDIS-11-16-1611-PDN

[30] Alam, M.W., Rehman, A., Malik, A.U., Aslam, S., Sarwar, M., Ali, S., Khan, M.A., Hameed, A. and Sarfraz, S. (2018) First Report of Alternaria alternate Causing Postharvest Fruit Rot of Peach in Pakistan. Journal of Plant Pathology, 8, 1. https://doi.org/10.1007/s42161-018-0160-5

[31] Yang, J.L., Sun, C., Zhang, Y.Y., Fu, D., Zheng, X.D. and Yu, T. (2017) Induced Resistance in Tomato Fruit by $\gamma$-Aminobutyric Acid for the Control of Alternaria Rot Caused by Alternaria alternata. Food Chemistry, 221, 1014-1020. https://doi.org/10.1016/j.foodchem.2016.11.061

[32] Timmer, L.W., Peever, T.L., Solerl, Z. and Akimitsu, K. (2003) Alternaria Diseases of Citrus-Novel Pathosystems. Phytopathologia Mediterranea, 42, 99-112.

[33] Bertero, A., Spicer, L.J. and Caloni, F. (2018) Fusarium Mycotoxins and in Vitro Species-Specific Approach with Porcine Intestinal and Brain in Vitro Barriers: A Review. Food and Chemical Toxicology, 121, 666-675. https://doi.org/10.1016/j.fct.2018.09.050

[34] Chai, A.L., Li, P.L., Guo, W.T., Li, B.J. and Aisimutuola, P. (2018) First Report of Fusarium acuminatum Wilt in the Broomrape Parasite of Processing Tomato in China. Plant Disease, 102, 676. https://doi.org/10.1094/PDIS-08-17-1244-PDN

[35] Du, M., Ren, X.Y., Sun, Q.H., Wang, Y. and Zhang, R.F. (2012) Characterization of 
Fusarium spp. Causing Potato Dry Rot in China and Susceptibility Evaluation of Chinese Potato Germplasm to the Pathogen. Potato Research, 55, 173-184. https://doi.org/10.1007/s11540-012-9217-6

[36] Wang, C.W., Ai, J., Fan, S.T., Lv, H.Y., Qin, H.Y., Yang, Y.M. and Liu, Y.X. (2015) Fusarium acuminatum: A New Pathogen Causing Postharvest Rot on Stored Kiwifruit in China. Plant Disease, 99, 1644. https://doi.org/10.1094/PDIS-01-15-0021-PDN

[37] Wang, Y., Wang, C.W., Gao, J. and Yang, L.N. (2016) First Report of Fusarium acuminatum Causing Postharvest Fruit Rot on Stored Vaccinium corymbosum in China. Plant Disease, 100, 2527. https://doi.org/10.1094/PDIS-04-16-0529-PDN

[38] Wang, Y., Guan, Y.M., Lu, B.H. and Gao, J. (2016) First Report of Ginseng (Panax ginseng) Root Rot Caused by Fusarium acuminatum in China. Plant Disease, 100, 525. https://doi.org/10.1094/PDIS-03-15-0273-PDN

[39] Akbar, A., Hussain, S., Ullah, K., Fahim, M. and Ali, G.S. (2018) Detection, Virulence and Genetic Diversity of Fusarium Species Infecting Tomato in Northern Pakistan. PLoS ONE, 13, e0203613. https://doi.org/10.1371/journal.pone.0203613

[40] Braun, H., Woitsch, L., Hetzer, B., Geisen, R., Zange, B. and Schmidt-Heydt, M. (2018) Trichoderma harzianum: Inhibition of Mycotoxin Producing Fungi and Toxin Biosynthesis. International Journal of Food Microbiology, 280, 10-16. https://doi.org/10.1016/j.ijfoodmicro.2018.04.021

[41] Srivastava, M., Shahid, M., Pandey, S., Singh, A., Kumar, V., Gupta, S.J. and Maurya, M. (2014) Trichoderma Genome to Genomics: A Review. Journal of Data Mining in Genomics \& Proteomics, 5, 162. https://doi.org/10.4172/2153-0602.1000162

[42] Sharma, V., Salwan, R. and Sharma, P.N. (2016) Differential Response of Extracellular Proteases of Trichoderma harzianum against Fungal Phytopathogens. Current Microbiology, 73, 419-425. https://doi.org/10.1007/s00284-016-1072-2 


\section{Appendix}

(a) (bp)

1000

750

500

250

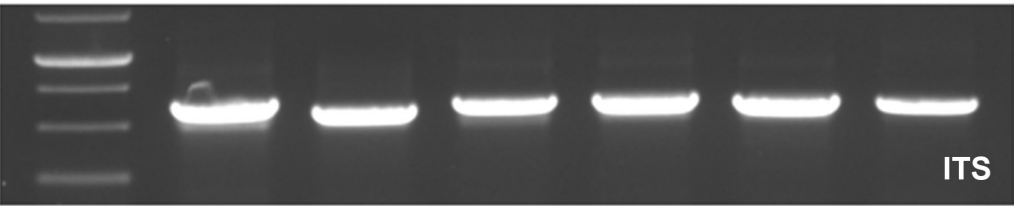

(b)

(bp)

10000
5000

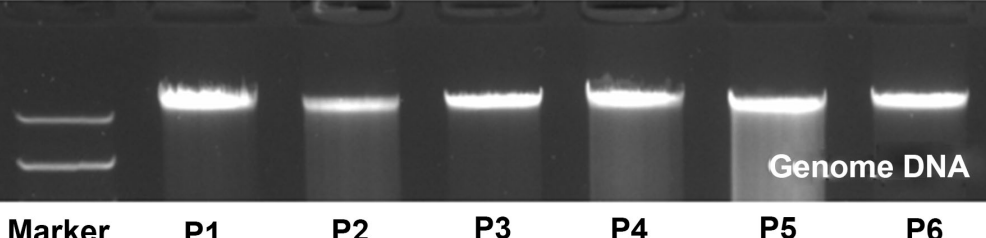

Marker P1

P2

P3

P4

P5

P6

Figure S1. The rDNA-ITS molecular characters of isolated pathogens. (a) The amplified products using ITS universal primers; (b) The genome DNA of isolated pathogens. P1: Penicillium expansum; P2: Botrytis cinerea; P3: Botryosphaeria dothidea; P4: Diaporthe phaseolorum; P5: Alternaria alternata; P6: Fusarium acuminatum.
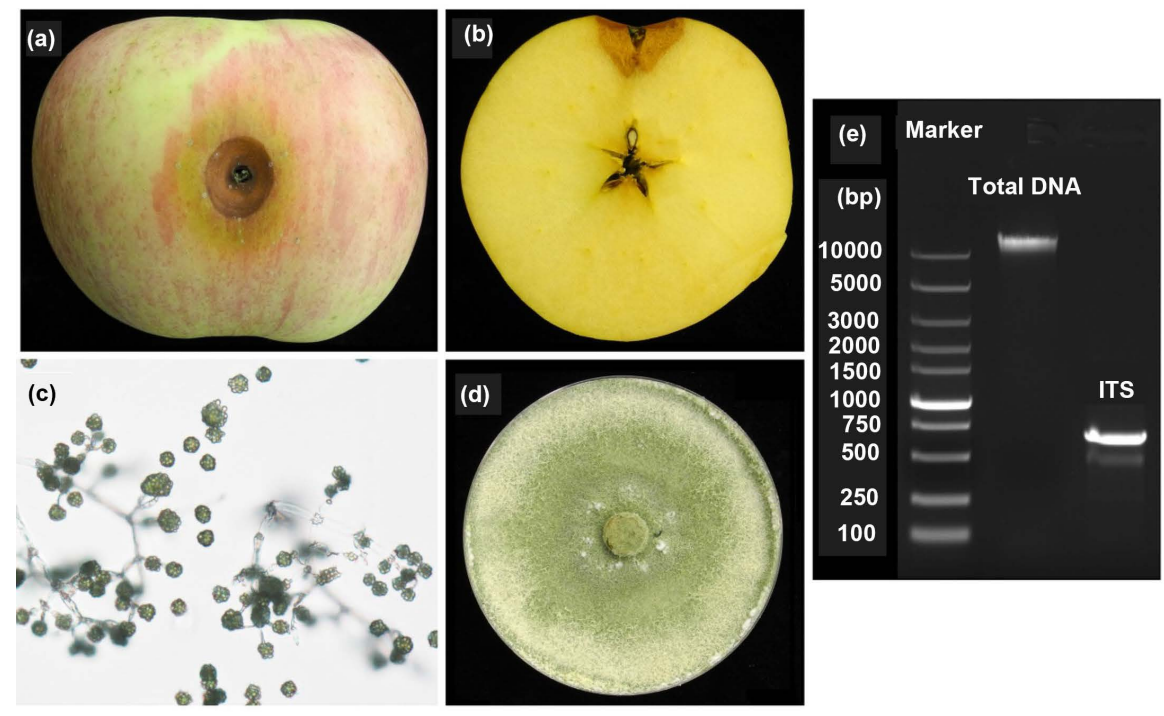

Figure S2. The phenotype and rDNA-ITS molecular character of Trichoderma harzianum. (a) and (b) The symptom of T. harzianum on surface or cross-section of apple fruit with lower pathogenicity after 12 days of inoculation; (c) The mycelia and sporangia of $T$. harzianum; (d) The colony of T. harzianum; (e) The amplified ITS product using universal primers. 
Table S1. The ITS sequences of identified pathogens.

\begin{tabular}{|c|c|}
\hline Pathogen & ITS sequences \\
\hline P1 & $\begin{array}{l}\text { CTGATCCGAGGTCACCTGGATAAAATTTGGGTTGATCGGCAAGCGCCGGCCGGGCCTACAGAGCGGGTGACAAAGCCCC } \\
\text { ATACGCTCGAGGACCGGACGCGGTGCCGCCGCTGCCTTTCGGGCCCGTCCCCCGGAATCGGAGGACGGGGCCCAACAC } \\
\text { ACAAGCCGGGCTTGAGGGCAGCAATGACGCTCGGACAGGCATGCCCCCCGGAATACCAGGGGGCGCAATGTGCGTTCA } \\
\text { AAGACTCGATGATTCACTGAATTTGCAATTCACATTACGTATCGCATTTCGCTGCGTTCTTCATCGATGCCGGAACCAAG } \\
\text { AGATCCGTTGTTGAAAGTTTTAAATAATTTATATTTTCACTCAGACGACAATCTTCAGGCAGAGTTCGGGGGTGTCTTCG } \\
\text { GCGGGCGCGGGCCCGGGGGCGTGAGCCCCCCGGCGGCCAGTTAAGGCGGGCCCGCCGAAGCAACGAGGTAAATAAACA } \\
\text { CGGGTGGGAGGTTGGACCCAAAGGGCCCTCACTCGGTAATGATCCT }\end{array}$ \\
\hline P2 & $\begin{array}{l}\text { CTGATCCGAGGTCACCATAGAAAAATTTGGGTTTTGGCAGAAGCACACCGAGAACCTGTAACGAGAGATATTACTACGT } \\
\text { TCAGGACCCAGCGGCGCCGCCACTGATTTTAGAGCCTGCCATTACTGACATAGACTCAATACCAAGCTAAGCTTGAGGG } \\
\text { TTGAAATGACGCTCGAACAGGCATGCCCCCCGGAATACCAAGGGGCGCAATGTGCGTTCAAAGATTCGATGATTCACTG } \\
\text { AATTCTGCAATTCACATTACTTATCGCATTTCGCTGCGTTCTTCATCGATGCCAGAACCAAGAGATCCGTTGTTGAAAGT } \\
\text { TTTAACTATTATATAGTACTCAGACGACATTAATAAAAAGAGTTTTGGTATTCTCTGGCGAGCATACAAGGCCCGGAGGC } \\
\text { AGCTCGCCAAAGCAACAAAGTAATAATACACAAGGGTGGGAGGTCTACCCTTTCGGGCATGAACT }\end{array}$ \\
\hline P3 & $\begin{array}{l}\text { CCTACCTGATCCGAGGTCACCTTGGAGAAAAGTTCAGAAGGTTCGTCCGGCGGGCGACGCCCTGCGCTCCGAAGCGAGA } \\
\text { TGTATGTTCTACTACGCTTGAGGCAAGACGCCACCGCCGAGGTCTTTGAGGCGCGCCCGCAAAGGACGGTGCCCAATAC } \\
\text { CAAGCAGAGCTTGAGGGTTGTAATGACGCTCGAACAGGCATGCCCTTCGGAATACCAAAGGGCGCAATGTGCGTTCAAA } \\
\text { GATTCGATGATTCACTGAATTCTGCAATTCACATTACTTATCGCATTTCGCTGCGTTCTTCATCGATGCCAGAACCAAGA } \\
\text { GATCCGTTGTTGAAAGTTTTAGTTTATTAAATGTTTTTCAGACTGCATCGTTTACTGACTGGAGTTTGATGGTCCTCTGGC } \\
\text { GGGCGCTGGCCACCCCCCCGG }\end{array}$ \\
\hline $\mathrm{P} 4$ & $\begin{array}{l}\text { CTGATCCGAGGTCAATTTTCAGAAGTTGGGGGTTTAACGGCAGGGCACCGCCAGGGCCTTCCAGAGCGAGGGTTTAACT } \\
\text { ACTGCGCTCGGGGTCCTGGCGAGCTCGCCAATGAATTTCAGGGCCTGCATCCCGCGAGAGACGCAGTGCCCCAACACCA } \\
\text { AGCCAGGCTTGAGGGTTGAAATGACGCTCGAACAGGCATGCCCTCCGGAATACCAGAGGGCGCAATGTGCGTTCAAAG } \\
\text { ATTCGATGATTCACTGAATTCTGCAATTCACATTACTTATCGCATTTCGCTGCGTTCTTCATCGATGCCAGAACCAAGAG } \\
\text { ATCCGTTGTTGAAAGTTTTGATTCATTTATGTTTATTTCTCAGAGTTTCAGTATAAAAACAAGAGTTAACTTGGCCGCCG } \\
\text { GCGGGCTGCTCCCCGTCTCCGGGGGGCCCCCAGGGGGGCCGGCCTGCGCCGAGGCAACAGTAAGGTATAAGTTCACAA } \\
\text { AGGGTTTCTGGGTGCGCCTGGGGCGCGTTCCAGCAA }\end{array}$ \\
\hline P5 & $\begin{array}{l}\text { CCTACTGGATCCGAGGTCAAAGTTGAAAAAAAGGCTTAATGGATGCTAGACCTTTGCTGATAGAGAGTGCGACTTGTGC } \\
\text { TGCGCTCCGAAACCAGTAGGCCGGCTGCCAATTACTTTAAGGCGAGTCTCCAGCAAAGCTAGAGACAAGACGCCCAACA } \\
\text { CCAAGCAAAGCTTGAGGGTACAAATGACGCTCGAACAGGCATGCCCTTTGGAATACCAAAGGGCGCAATGTGCGTTCAA } \\
\text { AGATTCGATGATTCACTGAATTCTGCAATTCACACTACTTATCGCATTTCGCTGCGTTCTTCATCGATGCCAGAACCAAG } \\
\text { AGATCCGTTGTTGAAAGTTGTAATTATTAATTTGTTACTGACGCTGATTGCAATTACAAAAGGTTTATGTTTGTCCTAGT } \\
\text { GGTGGGCGAACCCACCAAGGAAACAAGAAGTACGCAAAAGACAAGGGTGAATAATTCAGCAAGGCTGTAACCCCGAGA } \\
\text { GGTTCCAGCCCGCCTTCATATTTGTGTA }\end{array}$ \\
\hline P6 & $\begin{array}{l}\text { CTGATCCGAGGTCACATTCAGAAGTTGGGGTTTTACGGCATGGCCGCGCCGCGTTCCAGTTGCGAGGTGTTAGCTACTA } \\
\text { CGCAATGGAGGCTGCAGCGAGACCGCCAATGTATTTCGGGGGCGGCACCGCCCAGAAGGGCAGAGCCGATCCCCAACA } \\
\text { CCAAACCCGGGGGCTTGAGGGTTGAAATGACGCTCGAACAGGCATGCCCGCCGGAATACCAGCGGGCGCAATGTGCGT } \\
\text { TCAAAGATTCGATGATTCACTGAATTCTGCAATTCACATTACTTATCGCATTTTGCTGCGTTCTTCATCGATGCCAGAAC } \\
\text { CAAGAGATCCGTTGTTGAAAGTTTTGATTTATTTGTTTGTTTTACTCAGAAGTTACAATAAGAAACATTAGAGTTTGGGT } \\
\text { CCTCTGGCGGGCCGTCCCGTTTTACGGGGCGCGGGCTGATCCGCCGAGGCAACATTAAGGTATGTTCACAGGGGTTTGG } \\
\text { GAGTTGTAAACTCGGTAATG }\end{array}$ \\
\hline P7 & $\begin{array}{l}\text { TTTGATATGCTTAAGTTCAGGGGGTATTCTACCTGATCCGAGGTCACATTTTCAGAAGTTGGGTGTTTAACGGCTGTGGA } \\
\text { CGCGCCGCGCTCCCGATGCGAGTGTGCAAACTACTGCGCAGGAGAGGCTGCGGCGAGACCGCCACTGTATTTCGGAGAC } \\
\text { GGCCACCGCCAAGGCAGGGCCGATCCCCAACGCCGACCCCCCGGAGGGGTTCGAGGGTTGAAATGACGCTCGGACAGG } \\
\text { CATGCCCGCCAGAATACTGGCGGGCGCAATGTGCGTTCAAAGATTCGATGATTCACTGAATTCTGCAATTCACATTACTT } \\
\text { ATCGCATTTCGCTGCGTTCTTCATCGATGCCAGAACCAAGAGATCCGTTGTTGAAAGTTTTGATTCATTTTCGAAACGCC } \\
\text { TACGAGAGGCGCCGAGAAGGCTCAGATTATAAAAAAAACCCGCGAGGGGGTATACAATAAGAGTTTTGGTTGGTCCTCC } \\
\text { GGCGGGCGCCTTGGTCCGGGGCTGCGACGCACCCGGGGCAGAGATCCCGCCGAGGCAACAGTTTGGTAACGTTCACATT } \\
\text { GGGTTTGGGAGTTGTAAACTCGGTAATGATCCCTCCGCTGGTTCACCAACGGAGACCTTGTTA }\end{array}$ \\
\hline
\end{tabular}

P1: Penicillium expansum; P2: Botrytis cinerea; P3: Botryosphaeria dothidea; P4: Diaporthe phaseolorum; P5: Alternaria alternata; P6: Fusarium acuminatum. P7: Trichoderma harzianum. 